\title{
The Potyvirus Particle Recruits the Plant Translation Initiation Factor elF4E by Means of the VPg covalently Linked to the Viral RNA
}

\author{
Geneviève Tavert-Roudet, ${ }^{1}$ Agnès Anne, ${ }^{2}$ Amandine Barra, ${ }^{1}$ Arnaud Chovin, ${ }^{2}$ Christophe Demaille, ${ }^{2}$ \\ and Thierry Michon ${ }^{1, \dagger}$
}

'UMR 1332 BFP, INRA, Université Bordeaux, 33883 Villenave d'Ornon, France; and '2Laboratoire d'Electrochimie Moléculaire, UMR 7591 CNRS, Université Paris Diderot, Sorbonne Paris Cité, 15 rue Jean-Antoine de Baiff, F-75205 Paris Cedex 13, France

Accepted 12 June 2017.

\begin{abstract}
The viral protein genome-linked (VPg) of potyviruses is a protein covalently linked to the $5^{\prime}$ end of viral RNA. It interacts with eIF4E, a component of the cellular translation initiation complex. It has been suggested that the 5' RNA-linked VPg could mimic the cellular mRNA cap, promoting synthesis of viral proteins. Here, we report evidence for recruitment of the plant eIF4E by Lettuce mosaic virus (LMV, potyvirus) particles via the 5' RNA-linked VPg. Analysis of the viral population was performed by enzyme-linked immunosorbent assay-based tests, either with crude extracts of LMV-infected tissues or purified viral particles. In both cases, LMV-VPg and LMV-eIF4E subpopulations could be detected. After reaching a maximum within the first 2 weeks postinoculation, these populations decreased and very few labeled particles were found later than 3 weeks postinoculation. The central domain of VPg (CD-VPg) was found to be exposed at the surface of the particles. Using a purified recombinant lettuce eIF4E and CD-VPg-specific antibodies, we demonstrate that the plant factor binds to the VPg via its central domain. Moreover, the plant eIF4E factor could be imaged at one end of the particles purified from LMV plant extracts, by immunoredox atomic force microscopy coupled to scanning electrochemical microscopy. We discuss the biological significance of these results.
\end{abstract}

The genus Potyvirus represents one of the largest and most economically destructive genera of plant viruses. The potyviral genome encodes a small set of 11 different proteins responsible for highjacking host resources for its replication. Many efforts have been made to better understand the molecular aspects of the cellular virus cycle and to analyze the virus-host interactome (Elena and Rodrigo 2012; Ivanov et al. 2014; Jiang and Laliberté 2011; Mäkinen and Hafrén 2014; Martínez et al. 2016; Wang 2015). Although the literature does not report many studies on potyvirus particle contribution to the infectious cycle, the mature viral particle is a key player in processes such as protein translation and genome replication control (Besong-Ndika et al. 2015), cell-to-cell and systemic movement within the plant (Dolja et al. 1994), or interaction with an aphid vector

${ }^{\dagger}$ Corresponding author: T. Michon; E-mail: thierry.michon@inra.fr

*The $\boldsymbol{e}$-Xtra logo stands for "electronic extra" and indicates that one supplementary figure and one supplementary table are published online.

This article is in the public domain and not copyrightable. It may be freely reprinted with customary crediting of the source. The American Phytopathological Society, 2017.
(Ruiz-Ferrer et al. 2005). It is likely that a more detailed characterization of nonstructural protein factors copurifying with virus particles could help to decipher some molecular mechanisms of the viral cycle. However, although promising (Brizard et al. 2006), this approach has not been much explored so far. In the present work, we looked for the presence of eIF4E, a subunit of the host plant translation initiation complex, on native potyvirus particles. Potyviruses possess a single-stranded, polyadenylated, positive-sense genomic RNA that is covalently linked at its $5^{\prime}$ end to a viral protein, the viral protein genome-linked (VPg) (Murphy et al. 1991). The potyviral VPg is a virulence factor that has been shown to interact with several viral and host factors and is assumed to be a multifunctional protein involved in all essential steps of the virus infection cycle, translation, replication, and movement (Bosque et al. 2014; Ivanov et al. 2014; Jiang and Laliberté 2011). Among cellular host factors necessary to the virus, VPg recruits the eukaryotic translation initiation factor 4E (eIF4E) or its isoform, eIF(iso)4E, in an interaction that is crucial for infection (Charron et al. 2008; Léonard et al. 2000). Eukaryotic mRNAs are capped at their $5^{\prime}$ end with 7-methylated guanine (m7G). The recognition of this $\mathrm{m} 7 \mathrm{G}$ functional group by eIF4E leads to the recruitment of the $40 \mathrm{~S}$ ribosomal subunit onto the mRNA (Browning and Bailey-Serres 2015). The general structural similarity between the potyvirus genomic RNA and eukaryotic mRNAs suggests that VPg may serve as a cap-like structure, allowing the virus to recruit the cell translation machinery. A VPg-mediated enhancement of viral genome expression was observed concomitant with a cellular mRNA expression shutdown. It was suggested that VPg could inhibit endogenous mRNA translation by complexing available eIF4E (Eskelin et al. 2011). It was previously reported that VPg is exposed at one end of the virus particle (Nault et al. 2015; Torrance et al. 2006). In this study, we investigated the possible eIF4E binding to the LMV particle. An analysis of the particle population was conducted on LMV-infected plants. By looking for VPg and eIF4E proteins associated to the viral particle and locating the eIF4E binding site, we demonstrated that plant eIF4E interacts with the VPg linked to the RNA of the LMV potyvirus particle. The possible functional implications of this interaction are discussed.

\section{RESULTS}

The LMV VPg and cellular eIF4E interact with viral forms associated with coat proteins (CPs) in planta.

The presence of VPg and eIF4E within complexes, including CPs, was first assessed in crude extracts from infected plants. 
A two-sites triple antibody sandwich-enzyme-linked immunosorbent assay (2S-TAS-ELISA) (Roudet-Tavert et al. 2002) was performed on extracts of Nicotiana benthamiana systemically infected with the LMV-AF199 isolate (Krause-Sakate et al. 2002), using anti-eIF4E ( $\alpha$ eIF4E) and anti-VPg $(\alpha$ VPg) antibodies (described below). These antibodies were used as baits in plastic wells (primary antibody), and anti-LMV $(\alpha \mathrm{CP})$ antibodies directed against the $\mathrm{CP}$ were used for $\mathrm{CP}$ detection (secondary antibody: conjugate). A significant signal was observed in both cases, revealing that populations of CPs present in infected plant extracts were physically associated with VPg, eIF4E, or both proteins (Fig. 1). Values obtained from CP complexes trapped in plastic wells through $\alpha \mathrm{CP}$ were comparatively much higher than values obtained when eIF4E or VPg antibodies were used, indicating signal amplification due to an excess of $\mathrm{CP}$ with respect to eIF4E and VPg. Indeed, as it uses $\alpha \mathrm{CP}$ for detection, the ELISA test probes for the total amount of $\mathrm{CP}$ in whatever form it participates. No significant signal was observed when performing the test with infected plant extracts using anti-green fluorescent protein $(\alpha \mathrm{GFP})$ antibodies in place of eIF4E/VPg antibodies or with healthy plant extracts (negative control).

\section{In planta, the amount of VPg- and eIF4E-labeled LMV particle subpopulations varies in the course of systemic infection.}

Within the infected plant, the virus is present as various nucleoprotein complexes, including transient CP-RNA structures and fully assembled particles. VPg proteins of Potato virus A (PVA) and Potato virus $Y$ (PVY)(Torrance et al. 2006) and, more recently, LMV (Nault et al. 2015) were previously found, associated with a subpopulation of particles purified from infected plants. Consequently, it is reasonable to assume that a part of the $\alpha$ VPg trapped structures containing CPs revealed in the infected plant extracts are composed of virus particles. In preliminary experiments, the analysis of eIF4E and VPg labeled subpopulations originating from heterogeneous leaf batches, in particular, samples originating from various harvesting times postinoculation or a leaf at various growth stages within a given plant, returned poorly reproducible results. Consequently, we assessed if the size of the VPg/eIF4E-LMV subpopulations varied during virus systemic infection. 2S-TAS-ELISA was performed on plant extracts from leaves located at different levels above the inoculated leaf, at 13, 21, and 28 days postinoculation (dpi). As illustrated in Figure 2A, the VPg- and eIF4E-labeled subpopulations reached a maximum during the first 13 dpi in leaves 2 and 3 . At 21 and $28 \mathrm{dpi}$, the proportion of these populations within the total virus load was reduced. This kinetic feature was observed in several independent experiments, showing that the subopulations of VPg- and eIF4E-labeled particles reached a maximum between 10 and 13 dpi (Supplementary Table S1). Such a synchronous occurrence of VPg- and eIF4E-labeled viral forms suggests a structural link between VPg and eIF4E on the virus. We then looked at the presence of these labeled forms in purified particle preparations. As high-quality particles were required, we used a soft purification protocol (descibed below). The viral RNA associated to these particles can be translated in vitro with high efficiency (Gabrenaite-Verkhovskaya et al. 2008). Following this procedure, potyviral particles of high physical integrity could be recovered, as was confirmed by transmission electron microscopy and atomic force microscopy (AFM) imaging. A time-dependency in the proportion of VPg- and eIF4Elabeled subpopulations was observed in purified LMV particles, with a maximum of labeled forms between 10 and $13 \mathrm{dpi}$ (Fig. 2B). A possibility exists that the extraction procedure put in closer contact virus particles, $\mathrm{VPg}$, and eIF4E, thereby favoring interactions. However, the time-dependency in the proportion of VPg- and eIF4E-labeled subpopulations in purified LMV particles substantiates a biological trait. Hence, we are inclined to consider that neither leaf tissue grinding nor the mild conditions used for particle preparation had a significant impact on the original VPg and eIF4E interaction with the particle.

\section{Mapping of VPg regions accessible on the viral particle surface.}

We investigated the trapping of the particles by $\alpha 21 \mathrm{DC}$, a monoclonal antibody previously described as recognizing an epitope of 17 amino acids within the VPg central region. This structural feature was demonstrated as being involved in the interaction between VPg and eIF4E (Roudet-Tavert et al. 2007). LMV particles, either originating from plant extracts (not shown) or from purified preparations, were efficiently trapped with both polyclonal $\alpha \mathrm{VPg}$ and $\alpha 21 \mathrm{DC}$ (Fig. 3). Consequently, a part of the particle population exposes the VPg central domain, which is available for $\alpha 21 \mathrm{DC}$ recognition. The subpopulation trapped by $\alpha \mathrm{VPg}$ could represent the totality of VPg-labeled LMV particles, including both particles with free VPg and particles with VPg bound to cellular eIF4E or other proteins, such as HCPro (the potyvirus helper component). The latter is known to compete with eIF4E for binding to the VPg central domain (Roudet-Tavert et al. 2007). As a matter of fact, the presence of HcPro was previously imaged together with VPg in a tip structure at one end of PVA and PVY particles by AFM and immuno-electron microscopy (Torrance et al. 2006). We previously showed that $\alpha 21 \mathrm{DC}$ is a competitive inhibitor of eIF4E association with VPg (Roudet-Tavert et al. 2007). A part of the particles could be trapped by $\alpha 21 \mathrm{DC}$, which indicated that an eIF4E-free VPg was exposed at their surface. We investigated the ability of this type of particle to bind to an exogenous eIF4E.

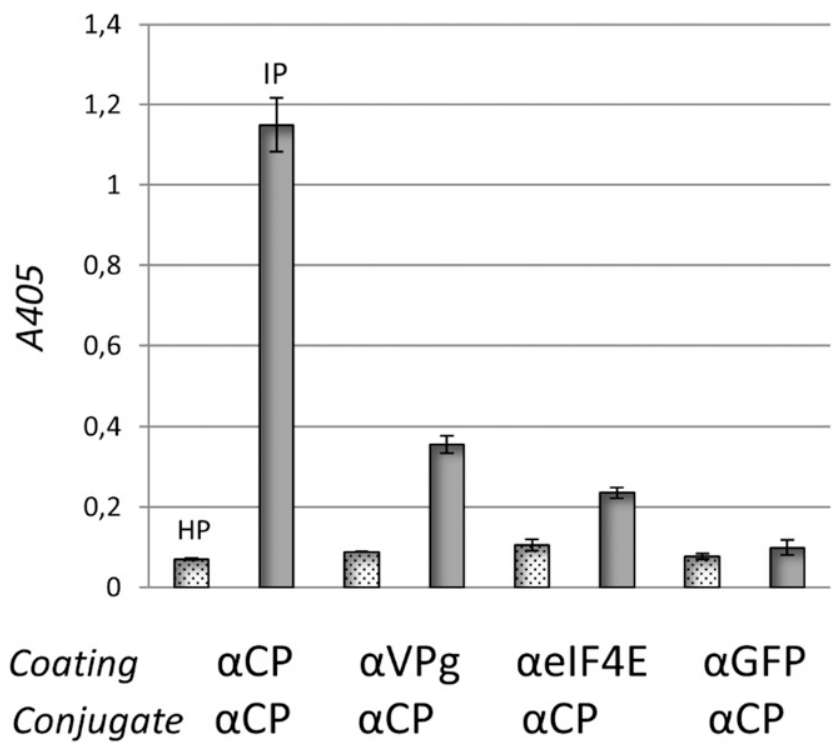

Fig. 1. In planta immunodetection of eIF4E and VPg associated with Lettuce mosaic virus (LMV) coat proteins. Immunodetection was performed using two-sites triple antibody sandwich-enzyme-linked immunosorbent assays. Wells were coated with antibodies as indicated. Crude extracts from LMV-inoculated plants (IP) (gray bars) or healthy plants (HP) (dotted bars). $N$. benthamiana plant extracts were added to the coated wells. The amount of LMV particles trapped in the wells was measured by colorimetry at 405 $\mathrm{nm}$, using LMV conjugate $(\alpha \mathrm{CP})$. A405 = absorbance at $405 \mathrm{~nm}$, mean values \pm standard deviation of three replicates obtained in a typical experiment. Negative control, anti-green fluorescent protein $(\alpha \mathrm{GFP})$ (coating). Student test: $\alpha \mathrm{CP} / \mathrm{HP}, P$ value $<0.00001 ; \alpha \mathrm{VPg} / \mathrm{HP}, P$ value $<$ $0.0001 ; \alpha$ IF4E/HP, $P$ value $<0.005 ; \alpha$ GFP/HP, $P$ value $>0.1$. 
A recombinant lettuce $\mathrm{eIF} 4 \mathrm{E}$ binds to the $\mathrm{LMV}$ particle.

The interaction of a recombinant form of lettuce eIF4E with LMV particles was tested in a 2S-TAS-ELISA experimental setup. Wells were precoated with aeIF4E to retain the recombinant eIF4E, and plant extracts or purified virus particles were added. A significant and reproducible signal was obtained, showing that the extract contained an eIF4E-free subpopulation of LMV particles (Fig. 4A). In the absence of recombinant eIF4E, the subpopulation of eIF4E-labeled particles was also revealed. The eIF4Efree subpopulation was analyzed. When purified particles were

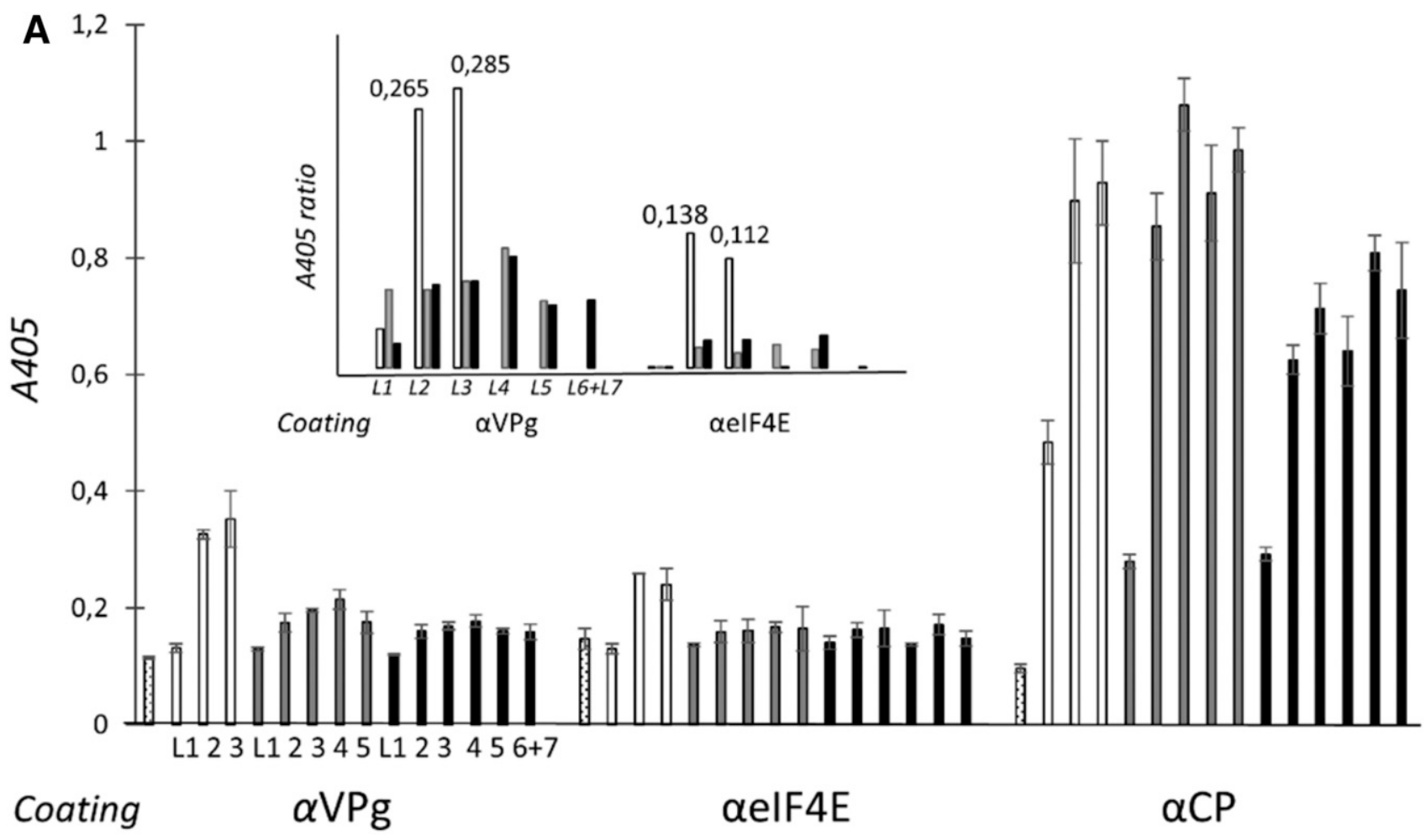

B

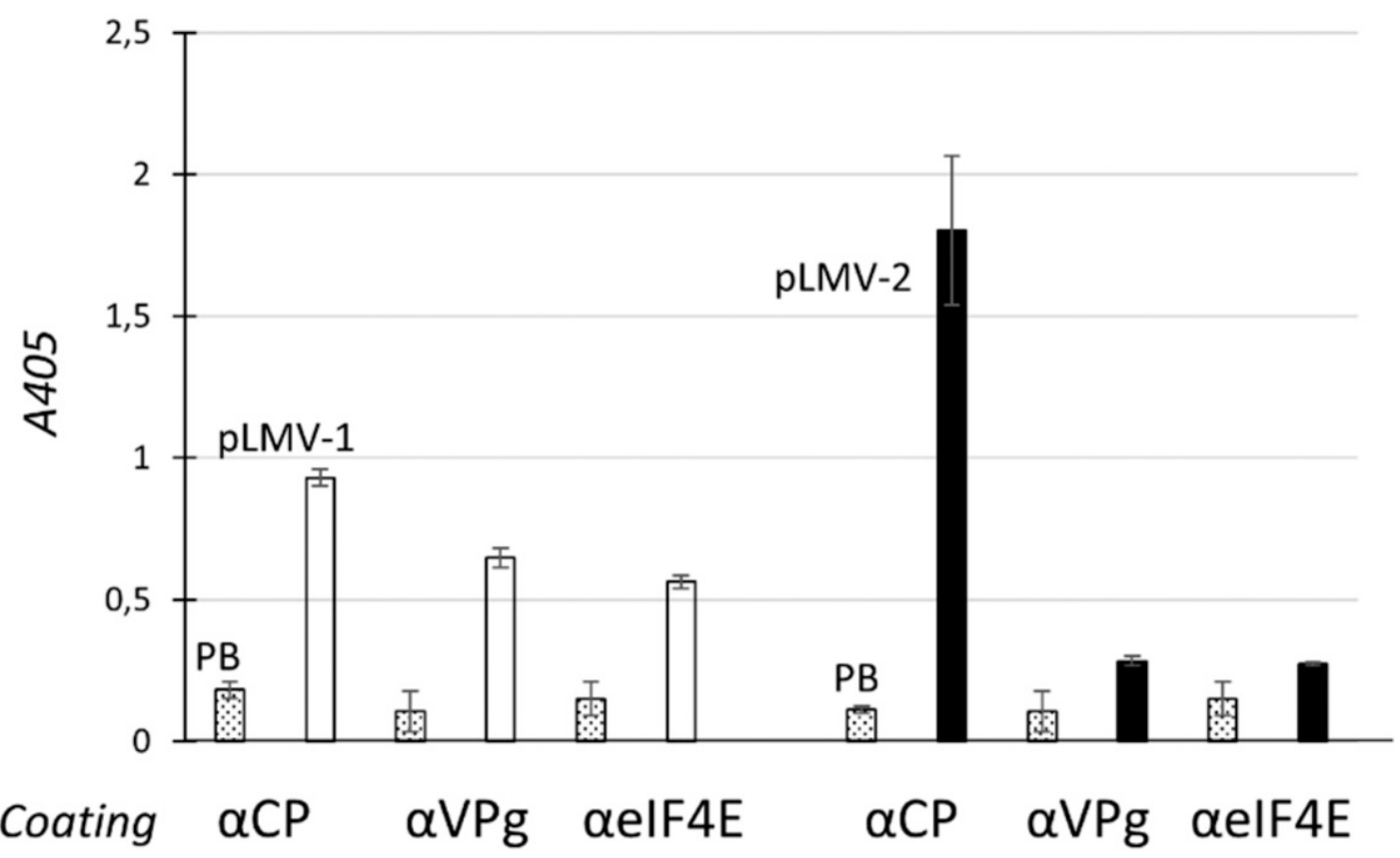

Fig. 2. Variation of populations of VPg and eIF4E-associated Lettuce mosaic virus (LMV) particles during virus migration in planta. A, Leaves from immediately above the inoculated leaves, numbered L1 through L7, were harvested at 13,21, and 28 days postinoculation (dpi), and their virus load was quantified by two-sites triple antibody sandwich-enzyme-linked immunosorbent assay (2S-TAS-ELISA); 13 dpi: L1, 2, 3 (white bars); 21 dpi: L1, 2, 3, 4, 5 (gray bars); 28 dpi: L1, 2, 3, 4, 5, 6+7 (black bars); healthy plant (dotted bars). Inset: to facilitate comparisons, absorbance at $405 \mathrm{~nm}(A 405)$ values corresponding to $\alpha \mathrm{VPg}$ - or $\alpha \mathrm{eIF} 4 \mathrm{E}-$ trapped LMV populations were divided by A405 values corresponding to the total $\alpha \mathrm{CP}$-trapped LMV population, corrected from heathy-plant unspecific signal (dotted bars). The highest ratios (13 dpi) are plotted above bars. B, LMV particles were purified from a pool of (L2 + L3) leaves of infected plants harvested at 10 to 13 dpi (pLMV-1, white bars) or at 21 to 25 dpi (pLMV-2, black bars) and the virus load was quantified by 2TAS-ELISA. Unspecific signal: PB = phosphate buffer (dotted bars); $A 405=$ mean values \pm standard deviation of three and four replicates ( $\mathrm{A}$ and $\mathrm{B}$, respectively). 
incubated with recombinant eIF4E before deposition into wells, a significant increase $(P$ value $<0.05)$ of the amount of trapped particles was observed (Fig. 4B). It is likely that this exogenous eIF4E supplementation permitted the recruitment of eIF4E-free particle subpopulations. It was deduced that at least two types of particles, eIF4E-free and pre-existing eIF4E-labeled particles, were present in the preparation.

Our results indicate that a subpopulation of virus particles could physically interact with an exogenous eIF4E. An eIF4E-interacting domain was previously mapped in the VPg central region (RoudetTavert et al. 2007). We show above (Fig. 3) that this region is exposed at the surface of the LMV particle. It is likely that the eIF4E-binding site displayed on the particle, is the VPg central domain. In planta, this domain could trap the endogenous eIF4E that we found associated to the particle. In order to validate our hypothesis, we performed ELISA competition experiments.

\section{Lettuce eIF4E competes with a monoclonal anti-VPg} central domain antibody for binding to the LMV particle.

We investigated whether LMV particle incubation with purified eIF4E could affect their trapping in wells coated with $\alpha 21 \mathrm{DC}$, the monoclonal antibody directed toward the VPg central domain. A significant decrease of the signal was observed both from plant extracts (Fig. 5A) and purified particles (Fig. 5B). This suggests that eIF4E and $\alpha 21 \mathrm{DC}$ compete for the binding to the LMV particle at a site located in the central region of the VPg. In a complementary assay, a preincubation of the plant extract with $\alpha 21 \mathrm{DC}$ prevented the trapping, in eIF4E-coated wells, of a significant amount of particles (Fig. 5A). From these results, we concluded that eIF4E binds to LMV particles through an interaction with the VPg central domain. Similarly, when purified particles were preincubated with a noninfected plant extract, a signal decrease was also observed (Fig. 5B). We hypothesize the involvement of cell proteins such as eIF4E or other factors competing with $\alpha 21 \mathrm{DC}$ for the binding to $\mathrm{VPg}$ central domain.

\section{The binding of eIF4E on LMV particle is imaged} by AFM-scanning electrochemical microscopy (SECM).

In order to visualize the location of eIF4E on the LMV particle surface, we made use of immunoredox molecule touching (Mt)/ AFM-SECM, a high-resolution correlative in-situ imaging technique we developed previously (Anne et al. 2011) and recently used to locate VPg at the extremity of LMV particles (Nault et al. 2015). This technique requires that the virus is first labeled by primary antibodies, specific to the sought viral protein. These primary antibodies are then made electrochemically "visible" using secondary antibodies carrying viewable tags consisting of redox ferrocene polyethylene glycol (Fc-PEG) chains. Hence, in the present work, LMV particles were adsorbed onto an ultraflat gold surface. The surface was subsequently saturated with bovine serum albumin (BSA), was then exposed to $\alpha \mathrm{eIF} 4 \mathrm{E}$ primary antibodies, and finally, was exposed to redox-labeled secondary antibodies. Mt/AFM-SECM imaging of the surface then allowed topography and current images to be simultaneously acquired in situ. As exemplified in Figure 6A, individual intact LMV particles could easily be identified from topography images. Interestingly, for a subpopulation of the particles examined, the correlated current image concomitantly showed a single bright current spot, which was specifically located at only one of the extremities of the virus particle (Fig. 6B and C; Supplementary Fig. S1A and B). The ELISA test used in this study cannot allow an accurate quantitation of the eIF4E-labeled particle subpopulation; however, AFM-SECM by simple counting gives access to a reliable value of $30 \%$ of the total particles within the sample (purification from 10- to 15-dpi extracts). For the remaining population of particles, no such current spot was visible anywhere in the current image. Therefore, the observed current spot corresponds to the selective electrochemical detection by the Mt/AFM-SECM probe of the immune complex formed between the redox-labeled antibody, aeIF4E antibodies, and eIF4E. Localization of this immune complex at one of the extremities of the LMV virus particles, where VPg was previously found (Nault et al. 2015), strongly supports, on a structural basis, the hypothesis of binding of eIF4E to VPg.

\section{DISCUSSION}

The potyvirus particle is made up of about 2,000 identical CP subunits, but, despite its filamentous monotonous structure, it harbors, at its very end, a set of viral factors (VPg, HcPro, cylindrical inclusion $[\mathrm{CI}]$ ) whose role is poorly understood (Gabrenaite-Verkhovskaya et al. 2008; Torrance et al. 2006). Among these proteins, the VPg was experimentally demonstrated

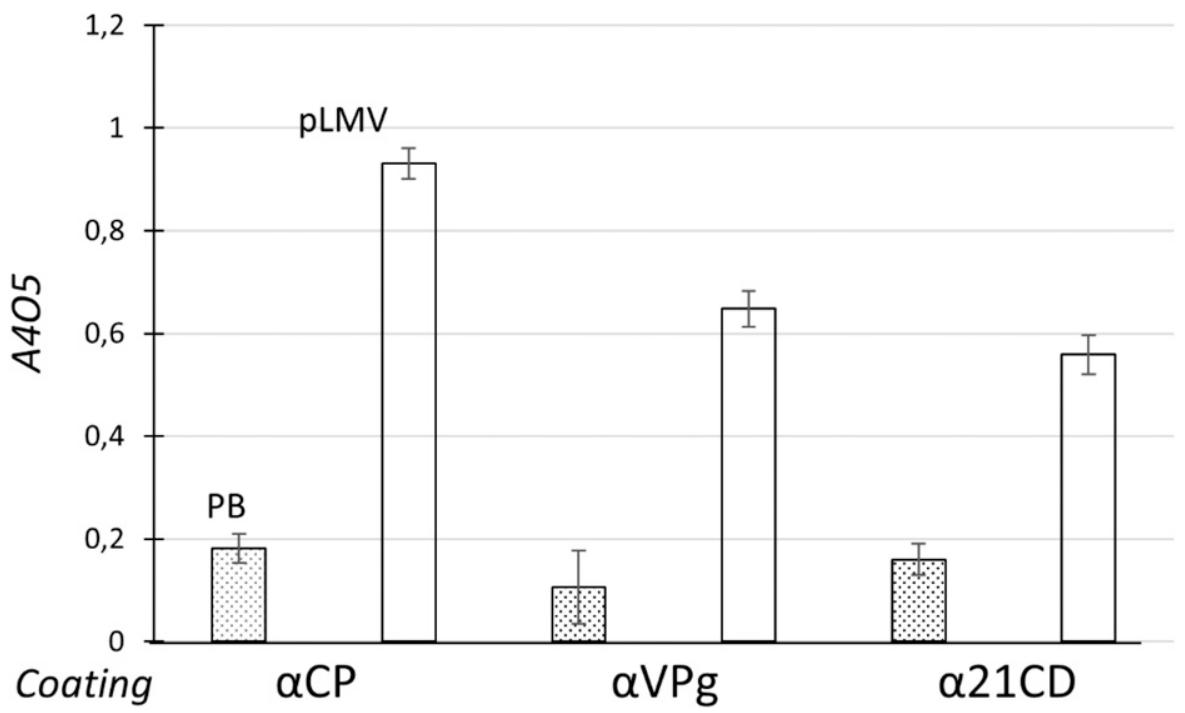

Fig. 3. VPg labeled Lettuce mosaic virus (LMV) subpopulation analysis. Monoclonal $\alpha 21 \mathrm{DC}$ and polyclonal $\alpha$ VPg antibodies raised against VPg were coated into the wells as indicated. The trapping of VPg labeled particles from LMV purified solution (pLMV) was quantified in a two-sites triple antibody sandwich-enzyme-linked immunosorbent assay. 21CD: monoclonal antibody directed against the VPg central domain. Unspecific signal: PB = phosphate buffer (dotted bars); A405 = absorbance at $405 \mathrm{~nm}$, mean values \pm standard deviation of three replicates. 
as being an intrinsically disordered protein (IDP) (Chroboczek et al. 2012; Hébrard et al. 2009; Rantalainen et al. 2008). IDPs are devoid of stable tertiary structures under physiological conditions and gain a stable three-dimensional structure only when they interact with their target molecules (Boehr and Wright 2008; Habchi et al. 2014).The VPg can be considered as a hub protein, interacting with both various host and viral factors as well as with the viral RNA (Charon et al. 2016; Jiang and Laliberté 2011; Martínez et al. 2016). Of special interest is the VPg-disordered central domain, shown in this study to be exposed to the particle surface. This domain interacts with various partners, such as HcPro and eIF4E (Roudet-Tavert et al. 2007). In this study, we have shown that eIF4E is found associated to the viral particle through a specific interaction with the VPg. This observation was made both from infected plant extracts and from purified viral particles. It is legitimate to ask what could be the biological meaning of this
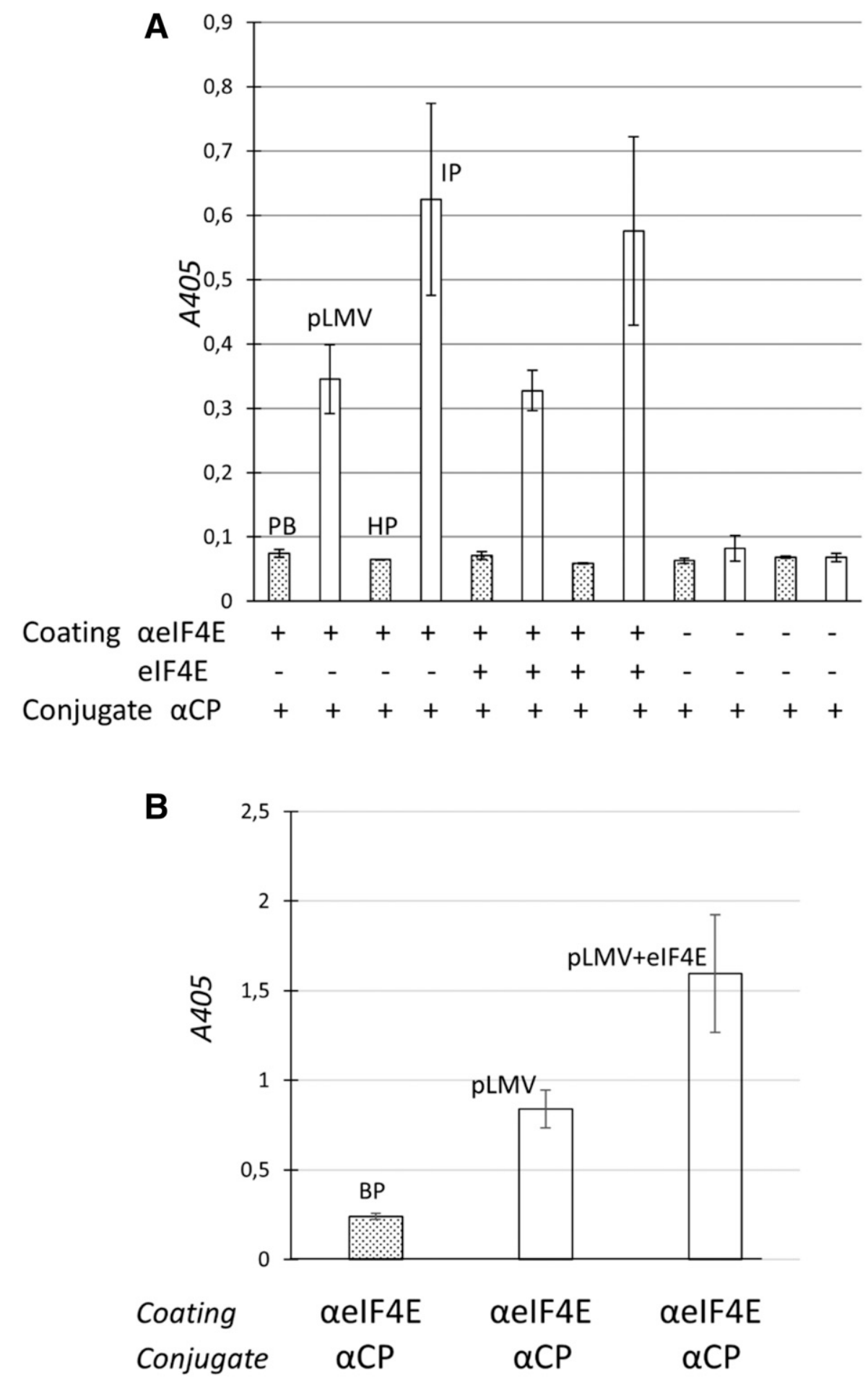

Fig. 4. In vitro interaction between a recombinant form of lettuce eIF4E and Lettuce mosaic virus (LMV) particles. A, Purified eIF4E was incubated, as indicated, into $\alpha$ eIF4E precoated wells and LMV-infected plant extract (IP) or purified particles (pLMV) were added. HP = healthy plant. B, Purified LMV particles (pLMV), either alone or preincubated with purified eIF4E, were incubated into aeIF4E precoated wells. The LMV-eIF4E particles retained in the wells were revealed by performing two-sites triple antibody sandwich-enzyme-linked immunosorbent-based assays as describe above. $A 405=$ absorbance at $405 \mathrm{~nm}$, mean values \pm standard deviation of between three and five replicates. $\mathrm{PB}=$ phosphate buffer, $P$ value $<0.05$. Dotted bars show unspecific signal. 
feature. Virus genome replication requires the synthesis of the viral replicase (RNA-dependent RNA polymerase [RdRP]). Consequently, RNA decapsidation and its subsequent translation into polyprotein must be two of the earliest events of the virus cycle. The potyvirus infectious cycle relays on a successful interaction between the VPg and eIF4E (Charron et al. 2008; Léonard et al. 2000). Because cellular mRNAs translation processes through an initiation step involving an interaction between the mRNA $5^{\prime}$ cap and eIF4E, it is tempting to hypothesize that the viral VPg could mimic this cap, thus highjacking the translation machinery. But it was clearly observed that, for several potyviruses, translation initiation of the viral RNA mainly processes through the positioning of the ribosome small subunit on an internal ribosome entry site (IRES) within the 5' untranslated region (UTR) and this independently of eIF4E (Zhang et al. 2015). However, mutations that, in the VPg from Tobacco ech virus, disturb eIF4E binding, abolish stimulation of IRES-mediated translation in wheat germ extract (Khan et al. 2008). In fact, the VPg was found to play a dual role in favoring viral 5' UTR-mediated translation while inhibiting cellular mRNA cap-dependent translation by decreasing the affinity of the eIF4E for the cap structure (Khan et al. 2008; Miyoshi et al. 2008). Perhaps most interestingly, an overexpression in trans of the PVA VPg in planta is associated with an enhancement of the viral RNA translation mediated by the IRES and this effect requires eIF4E (Eskelin et al. 2011). Alternatively, VPg covalently linked to the RNA could be only necessary for the first round of translation after disassembly of viral particles (Revers and García 2015). Regardless of the precise role of the VPg-eIF4E complex, taken together, these data provide strong evidence that this interaction is a key player in one or both genome translation or replication. Translation initiation factors are tightly regulated. It is likely that not
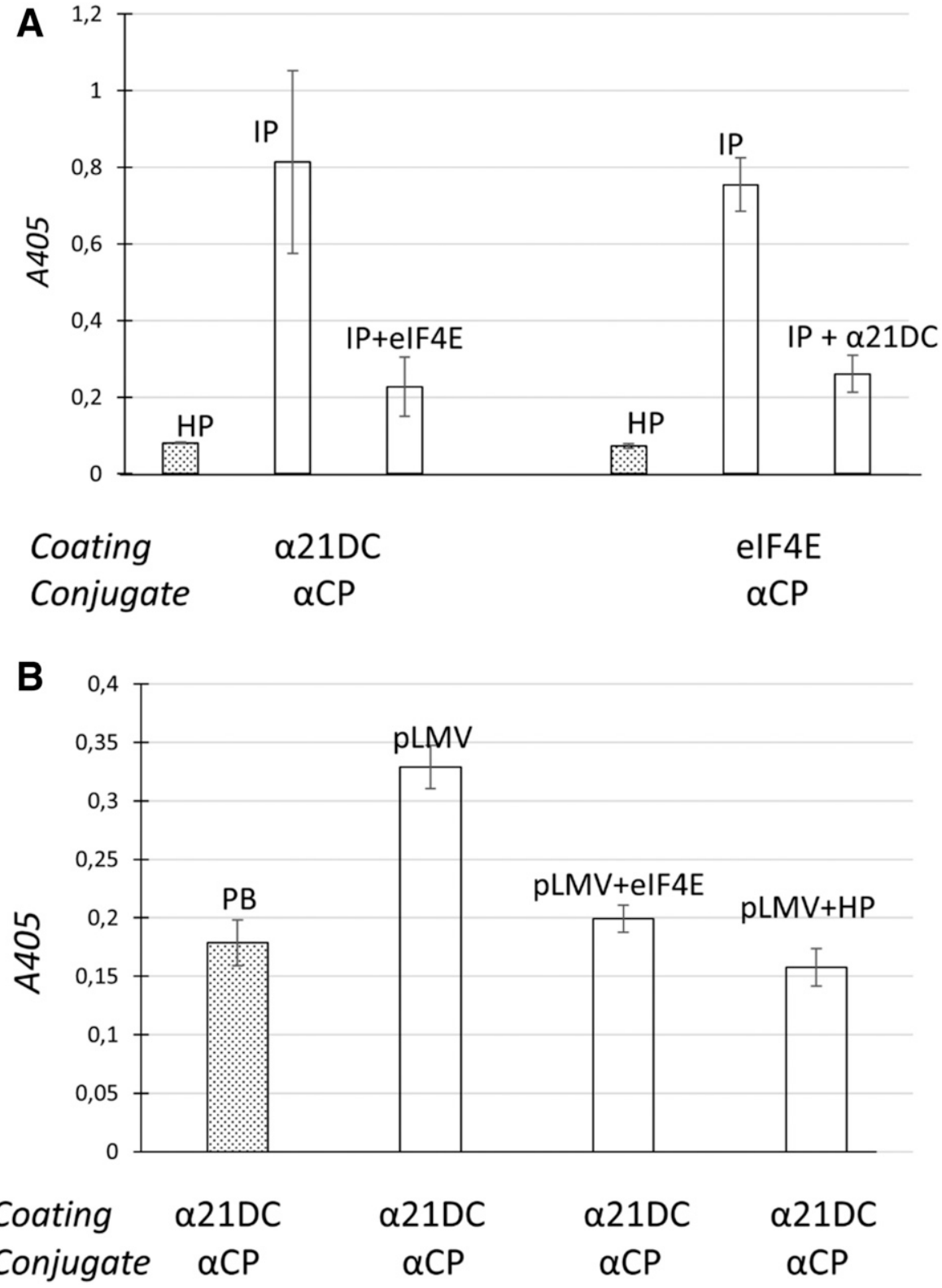

Fig. 5. Competition between a lettuce eIF4E and an anti VPg monoclonal antibody for binding to the Lettuce mosaic virus (LMV) particle. Purified lettuce eIF4E or $\alpha 21 \mathrm{DC}$ were coated into the wells and an overlay of A, LMV-infected plant crude extract (IP) or $\mathbf{B}$, LMV purified particles (pLMV) was added. When indicated, the extract was supplemented with purified eIF4E ( $\alpha 21 \mathrm{DC}$ coating), or $\alpha 21 \mathrm{DC}$ (purified eIF4E coating), or healthy plant extract ( $\alpha 21 \mathrm{DC}$ coating), before trapping. $A 405$ (absorbance at $405 \mathrm{~nm}$ ), mean values \pm standard deviation of five (A) or three replicates $(\mathrm{B})$. HP = healthy plant. Unspecific signal: $\mathrm{PB}=$ phosphate buffer (dotted bars). 
much free eIF4E is available for viral genome translation initiation. Indeed, it was observed that up to $68 \%$ of eIF4E forms (Iborra et al. 2001) are sequestered in the nucleus and are involved in various functions such as premRNA splicing or nonsense mediated decay, among others (Strudwick and Borden 2002). In the cytoplasm, eIF4E is the mRNA cap target within the eIF4F translation initiation complex. Given the strong affinity ( $K_{\mathrm{D}}$ in the nanomolar range) of the plant eIF4F subunits to each other, it seems unlikely that these complexes will dissociate once formed (Mayberry et al. 2007). In potyviruses, the natural mode of plant infection is virus particle transmission by aphid vectors. It was demonstrated that very few infectious particles (one to three) are introduced in the plant by the vector (Moury et al. 2007). In addition, the average number of potyvirus particles infecting a cell was estimated to be one (Tromas et al. 2014). This implies the presence of very few genome-associated VPg within an infected cell. Owing to the probable low concentration of available free eIF4E, the hypothesis that viral particles could bring into the cell a preassembled VPg-eIF4E binary complex linked to the viral RNA is worth considering. It can be inferred from our AFM-SECM data that about one-third of the particles are eIF4E-labeled at 13 dpi, which gives a high probability for the aphid to transfer this type of particle for acquisitions early after inoculation (disussed below). Immediately after cell penetration, the preassembled eIF4E-VPg complex could highjack cytoplasmic free eIF4G, allowing a translation initiation similar to that of mRNAs. This path could be subsequently replaced by the more competititve IRES-mediated translation.

The temporal distribution of CP, RdRP, and VPg at various time periods after inoculation was precisely investigated (Baunoch et al. 1991). It reveals that all proteins are detected simultaneously in systemic leaves from the fifth day after inoculation. All proteins increase in concentration until the seventh day and, then, show no further increase, with the exception of the CP. Although small concentrations of VPg and RdRP are detected in the cytoplasm, most of these proteins are relocated just after synthesis in the nucleus, in which they are sequestrated as nuclear inclusions NIa (VPg-Pro) and NIb (RdRP). At 14 days after infection, both proteins are found only as inclusions in the nucleus. The CPs are found at all stages of infection only in the cytoplasm. Our observations are in accordance with these data, as the subpopulation of VPg and eIF4E-labeled particles increase up to 14 $\mathrm{dpi}$, after which their amount decreases progressively with respect to the population of nonlabeled particles. Several features of virus biology suggest that a low translation efficiency could be required in the early step of infection. First, maintaining a low CP concentration within the cell is necessary. The single or so viral genome present within the cell at the start needs to be amplified. This amplification requires the biosynthesis of the virus replicase (RdRP) and other viral factors, such as CI and VPg, shown to be involved in replication. However, owing to the strict stoichiometry of the viral RNA polycistronic organization, each time a translation event occurs, the arising polyprotein contains one copy of each viral factor, including the CP. The presence on the RNA strand of very few $\mathrm{CP}$ monomers will prevent either the $5^{\prime}, 3^{\prime}$ progression of the ribosomes in the translation process or the $3^{\prime}, 5^{\prime} \mathrm{RdRP}$ progression for replication. It is likely that a weak translation efficiency mediated by the VPg-eIF4E interaction will favor a low concentration of CP. The particle assembly precludes the genome translation-replication steps, and it seems that the amount of CP is a regulator of the balance between genome amplification and particle formation through its phosphorylation state (Ivanov et al. 2003, 2001) and sequestration by the plant HSP70 and its cochaperone (Besong-Ndika et al. 2015; Hafrén et al. 2010). Second, maintaining a low concentration of RdRP should favor successful infection. Indeed, RdRP, owing to its high mutational rate $\left(10^{-5}\right)$, could easily jeopardize infection efficiency, as, for instance, $40 \%$ of potyviral genomes bearing a single nucleotide substitution are lethal (Carrasco et al. 2007). As the mutation rate is an intrinsic feature of the replicase, there is a tradeoff between the necessity of virus amplification and a low number of RdRP available in the cell, tunable through a low translation efficiency (Thébaud et al. 2010). Third, it was previously reported that high viral loads within primary infection sites prevent systemic movement (Lafforgue et al. 2012; Tromas et al. 2014). In the early stage, a part of the VPg produced could be coupled through phosphoester bound to the $5^{\prime}$ end of newly synthesized genomic RNAs (Murphy et al. 1991). Following the systemic spread of virus into the plant, more active translation would take over, favoring $\mathrm{CP}$ production and particle assembly
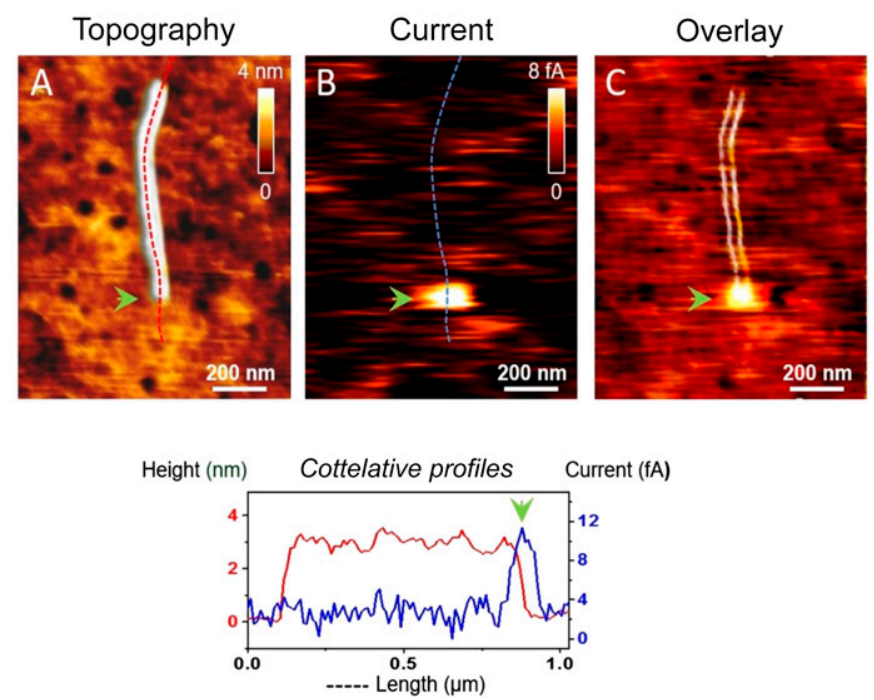

Fig. 6. In situ immunoredox molecule touching atomic force microscopy coupled to scanning electrochemical microscopy (Mt/AFM-SECM) imaging of an eIF4E-labeled Lettuce mosaic virus (LMV) particle immobilized on a gold surface. A, Topography image; $\mathbf{B}$, simultaneously acquired current image; and $\mathbf{C}$, overlay of the topography and current images showing the precise location of the current spot at one of the extremities of the virus particle. Bottom, Crosssections of the topography (red trace) and current (blue trace) images taken along the dotted line shown. The position where both topological and current signals correlate is shown by green arrows. 
around new-born genomes, while excess VPg and RdRP would be sequestered into the nucleus.

In conclusion, we provide, in this study, the first example of an interaction of potyviral particles with a cellular protein. Binding occurs via the central region of VPg, the viral protein covalently linked to the 5' end of the viral genomic RNA. This result supports the hypothesis of cap mimicry by the VPg. It suggests a sequestration of eIF4E by the particle, readily available for viral capdependent translation during the early steps of the viral life in planta.

\section{MATERIALS AND METHODS}

\section{Biological material.}

Nicotiana benthamiana four-leaves-old seedlings were mechanically inoculated (excluding the first oldest one) with Lettuce mosaic virus (LMV) strain AF199 (Krause-Sakate et al. 2002). Leaves were collected at 7 to $35 \mathrm{dpi}$ and were used as crude extracts for ELISA-based assays and particle purification. LMV purified particles were obtained from infected leaves as previously described (Nault et al. 2015). Symptomatic leaves $(300 \mathrm{~g})$ were homogenized in cold $0.1 \mathrm{M}$ phosphate buffer, $\mathrm{pH} 8$, containing $0.15 \%$ 2-mercaptoethanol and $0.01 \mathrm{M}$ EDTA ( $1 \mathrm{~g}$ of leaves in $2 \mathrm{ml}$ of buffer). Plant debris was spun down at 7,000 $\times g$ for $20 \mathrm{~min}$. After filtration through two layers of cheese cloth, Triton X-100 was added to the supernatant (final concentration $3 \%, \mathrm{vol} / \mathrm{vol}$ ) and was gently stirred at $4{ }^{\circ} \mathrm{C}$ for $3 \mathrm{~h}$. The remaining insoluble material was spun down at $12,000 \times g$ for $10 \mathrm{~min}$. Virus particles were precipitated overnight by the addition of PEG6000 (40 g per liter of supernatant) and $0.2 \mathrm{M} \mathrm{NaCl}$, under gentle stirring at $4{ }^{\circ} \mathrm{C}$ in the dark. Virus particles were recovered by centrifugation at $12,000 \times g$ for $20 \mathrm{~min}$. The virus pellet was suspended in one-tenth of the starting supernatant in $0.1 \mathrm{M}$ cold phosphate buffer, $\mathrm{pH} 8$, containing $1 \%$ Triton $\mathrm{X}-100$. This extract was centrifuged at $16,000 \times g$ for $1 \mathrm{~h}$ at $4^{\circ} \mathrm{C}$. The pellet was gently suspended overnight at $4^{\circ} \mathrm{C}$ in $0.1 \mathrm{M}$ phosphate, $\mathrm{pH} 8(5 \mathrm{ml}$ for $100 \mathrm{~g}$ of starting leaves). Ultracentrifuge tubes (Beckman rotorSW41 TI, $13-\mathrm{ml}$ volume) were filled with $5 \mathrm{ml}$ of $30 \%$ sucrose in $0.1 \mathrm{M}$ phosphate buffer, $\mathrm{pH}$ 8. The virus suspension $(2 \mathrm{ml}$ per tube) was gently layered on top of this sucrose cushion and was centrifuged at $150,000 \times g$ for $3 \mathrm{~h}$ at $4^{\circ} \mathrm{C}$. The pellet containing the virus particles was gently suspended overnight at $4^{\circ} \mathrm{C}$ in $2 \mathrm{ml}$ of $0.1 \mathrm{M}$ phosphate buffer, $\mathrm{pH}$. The virus particles obtained were purified through a 5 to $40 \%$ discontinuous sucrose gradient as follows. Centrifugation tubes (Beckman rotor SW 41 TI, 13-ml volume) were filled with sucrose solutions in phosphate buffer: from bottom to top, $1.5 \mathrm{ml}$ of $40 \%, 3 \mathrm{ml}$ of $30 \%, 3 \mathrm{ml}$ of $15 \%$, and $1.5 \mathrm{ml}$ of $5 \%$. A volume of 0.5 to $1 \mathrm{ml}$ of virus suspension was carefully layered on top of the gradient. The virus preparation was centrifuged at $80,000 \times g$ at $4^{\circ} \mathrm{C}$ for $1 \mathrm{~h}$. The pellet was suspended in the minimum amount of phosphate buffer $(0.1 \mathrm{M}), \mathrm{pH}$. The virus suspension was quantified by absorption spectrometry $(\varepsilon 0.1 \% 260 \mathrm{~nm}=2.6)$. Aliquots of $200 \mu \mathrm{l}$ of virus $(5$ to $6 \mathrm{mg} / \mathrm{ml})$ were stored at $-80^{\circ} \mathrm{C}$.

Lettuce eIF4E was expressed in Escherichia coli fused with a $\mathrm{N}$-ter hexahistidine tag, purified according to (German-Retana et al. 2008), and was used in ELISA interaction and competition assays (Roudet-Tavert et al. 2007).

\section{ELISA-derived binding assays.}

Monoclonal antibody directed against the VPg from LMV $(\alpha 21 \mathrm{DC})$, polyclonal $\alpha \mathrm{VPg}$, and polyclonal rabbit $\alpha \mathrm{eIF} 4 \mathrm{E}$ or against LMV coat protein ( $\alpha$-LMV) (Roudet-Tavert et al. 2007) were used as trapping antibodies in a 2S-TAS-ELISA assay (Roudet-Tavert et al. 2002). LMV-infected crude plant extract or purified LMV particles were added $(50 \mu \mathrm{g} / \mathrm{ml}$ in phosphate buffered saline [PBS] Tween $0.2 \%$ ). Polyclonal rabbit antibodies against LMV virus particles coupled to alkaline phosphatase (LMV conjugate) were used for particle detection. In some experiments, a specific GFP antibody $(\alpha \mathrm{GFP})$ was used as a negative control.

\section{ELISA test conditions for eIF4E interaction and competition assays.}

For interaction tests, purified recombinant eIF4E was incubated, either alone $(2 \mu \mathrm{g} / \mathrm{ml})$ or after a 2 -h premix at $37^{\circ} \mathrm{C}$ $(1 \mu \mathrm{g} / \mathrm{ml})$ with LMV particles in $\alpha \mathrm{eIF} 4 \mathrm{E}$ precoated wells. For ELISA competition assays, purified eIF4E $(4 \mu \mathrm{g} / \mathrm{ml})$ or $\alpha 21 \mathrm{DC}$ $(5 \mu \mathrm{g} / \mathrm{ml})$ were coated into the wells, followed by a saturation step (2\% BSA in PBS). LMV plant extract or purified LMV particles $(10 \mu \mathrm{g} / \mathrm{ml}$ in PBS Tween $0.2 \%)$, preincubated $(2 \mathrm{~h}$ $\left.37^{\circ}\right)$, respectively, with $\alpha 21 \mathrm{DC}(2 \mu \mathrm{g} / \mathrm{ml})$ or purified eIF4E $(1 \mu \mathrm{g} / \mathrm{ml})$ added. After a washing step, specifically retained LMV particles were revealed by the addition of LMV conjugate (dilution 1:500).

\section{Immunoredox Mt/AFM-SECM imaging.}

Polyclonal antirabbit antibody tagged with Fc-terminated PEG chains was used as a redox secondary antibody to reveal the location of the primary $\alpha \mathrm{eIF} 4 \mathrm{E}$ rabbit antibody. The FcPEGylated secondary antibody conjugate was prepared by reacting home-synthesized $\mathrm{NHS}-\mathrm{PEG}_{3400}-\mathrm{Fc}$ chains with an $\alpha$-rabbit antibody and purifying, following a procedure detailed elsewhere (Nault et al. 2015). For all operations including imaging, the medium was $10 \mathrm{mM}$ phosphate buffer (PB), $\mathrm{pH}$ 7.4. Purified LMV particles (from 12-dpi infected plants, content in eIF4E-labeled LMV, 20\% ELISA quantitation) $(60 \mu \mathrm{g} / \mathrm{ml})$ were first adsorbed onto a freshly peeled ultraflat gold surface for $10 \mathrm{~min}$. A 1-h BSA (1\% in PB) saturation step was then carried out. Subsequently, the surface was exposed to the primary aeIF4E antibody $(5 \mu \mathrm{g} / \mathrm{ml})$ for $1 \mathrm{~h}$. Finally, the surface was exposed overnight to the redox Fc-PEGylated secondary antibody $(20 \mu \mathrm{g} / \mathrm{ml})$. The Mt/AFM-SECM instrumental set-up, imaging protocol and conditions were as previously described (Nault et al. 2015).

\section{ACKNOWLEDGMENTS}

We thank C. Chesseron and T. Mauduit for taking care of the plants. Part of this work was funded by Agence Nationale Pour la Recherche (ANR, France) eVIRZYM project CE09, 2014.

\section{LITERATURE CITED}

Anne, A., Chovin, A., Demaille, C., and Lafouresse, M. 2011. High-resolution mapping of redox-immunomarked proteins using electrochemical-atomic force microscopy in molecule touching mode. Anal. Chem. 83:7924-7932.

Baunoch, D. A., Das, P., Browning, M. E., and Hari, V. 1991. A temporal study of the expression of the capsid, cytoplasmic inclusion and nuclear inclusion proteins of tobacco etch potyvirus in infected plants. J. Gen. Virol. 72:487-492.

Besong-Ndika, J., Ivanov, K. I., Hafrèn, A., Michon, T., and Mäkinen, K. 2015. Cotranslational coat protein-mediated inhibition of potyviral RNA translation. J. Virol. 89:4237-4248.

Boehr, D. D., and Wright, P. E. 2008. Biochemistry. How do proteins interact? Science 320:1429-1430.

Bosque, G., Folch-Fortuny, A., Picó, J., Ferrer, A., and Elena, S. F. 2014. Topology analysis and visualization of Potyvirus protein-protein interaction network. BMC Syst. Biol. 8:129.

Brizard, J. P., Carapito, C., Delalande, F., Van Dorsselaer, A., and Brugidou, C. 2006. Proteome analysis of plant-virus interactome: Comprehensive data for virus multiplication inside their hosts. Mol. Cell. Proteomics 5: 2279-2297.

Browning, K. S., and Bailey-Serres, J. 2015. Mechanism of cytoplasmic mRNA translation. Arabidopsis Book 13:e0176.

Carrasco, P., de la Iglesia, F., and Elena, S. F. 2007. Distribution of fitness and virulence effects caused by single-nucleotide substitutions in Tobacco Etch virus. J. Virol. 81:12979-12984. 
Charon, J., Theil, S., Nicaise, V., and Michon, T. 2016. Protein intrinsic disorder within the Potyvirus genus: From proteome-wide analysis to functional annotation. Mol. Biosyst. 12:634-652.

Charron, C., Nicolaï, M., Gallois, J. L., Robaglia, C., Moury, B., Palloix, A., and Caranta, C. 2008. Natural variation and functional analyses provide evidence for co-evolution between plant eIF4E and potyviral VPg. Plant J. 54:56-68.

Chroboczek, J., Hebrard, E., Makinen, C., Michon, T., and Rantalainen, K. 2012. Intrinsic disorder in genome-linked viral proteins VPgs of potyviruses. Pages 277-312 in: Flexible viruses: Structural disorder within viral proteins. Uversky, V. N., and Longhi, S., eds. John Wiley and Sons, Inc., Hoboken, New Jersey.

Dolja, V. V., Haldeman, R., Robertson, N. L., Dougherty, W. G., and Carrington, J. C. 1994. Distinct functions of capsid protein in assembly and movement of tobacco etch potyvirus in plants. EMBO J. 13:1482-1491.

Elena, S. F., and Rodrigo, G. 2012. Towards an integrated molecular model of plant-virus interactions. Curr. Opin. Virol. 2:719-724.

Eskelin, K., Hafrén, A., Rantalainen, K. I., and Mäkinen, K. 2011. Potyviral VPg enhances viral RNA Translation and inhibits reporter mRNA translation in planta. J. Virol. 85:9210-9221.

Gabrenaite-Verkhovskaya, R., Andreev, I. A., Kalinina, N. O., Torrance, L., Taliansky, M. E., and Mäkinen, K. 2008. Cylindrical inclusion protein of potato virus $\mathrm{A}$ is associated with a subpopulation of particles isolated from infected plants. J. Gen. Virol. 89:829-838.

German-Retana, S., Walter, J., Doublet, B., Roudet-Tavert, G., Nicaise, V., Lecampion, C., Houvenaghel, M. C., Robaglia, C., Michon, T., and Le Gall, O. 2008. Mutational analysis of plant cap-binding protein eIF4E reveals key amino acids involved in biochemical functions and potyvirus infection. J. Virol. 82:7601-7612.

Habchi, J., Tompa, P., Longhi, S., and Uversky, V. N. 2014. Introducing protein intrinsic disorder. Chem. Rev. 114:6561-6588.

Hafrén, A., Hofius, D., Rönnholm, G., Sonnewald, U., and Mäkinen, K. 2010. HSP70 and its cochaperone CPIP promote potyvirus infection in Nicotiana benthamiana by regulating viral coat protein functions. Plant Cell 22:523-535.

Hébrard, E., Bessin, Y., Michon, T., Longhi, S., Uversky, V. N., Delalande, F., Van Dorsselaer, A., Romero, P., Walter, J., Declerck, N., and Fargette, D. 2009. Intrinsic disorder in viral proteins genome-linked: Experimental and predictive analyses. Virol. J. 6:23-36.

Iborra, F. J., Jackson, D. A., and Cook, P. R. 2001. Coupled transcription and translation within nuclei of mammalian cells. Science 293:1139-1142.

Ivanov, K. I., Eskelin, K., Lõhmus, A., and Mäkinen, K. 2014. Molecular and cellular mechanisms underlying potyvirus infection. J. Gen. Virol. 95:1415-1429.

Ivanov, K. I., Puustinen, P., Gabrenaite, R., Vihinen, H., Rönnstrand, L., Valmu, L., Kalkkinen, N., and Mäkinen, K. 2003. Phosphorylation of the potyvirus capsid protein by protein kinase CK2 and its relevance for virus infection. Plant Cell 15:2124-2139.

Ivanov, K. I., Puustinen, P., Merits, A., Saarma, M., and Mäkinen, K. 2001. Phosphorylation down-regulates the RNA binding function of the coat protein of potato virus A. J. Biol. Chem. 276:13530-13540.

Jiang, J., and Laliberté, J. F. 2011. The genome-linked protein VPg of plant viruses-a protein with many partners. Curr. Opin. Virol. 1:347-354.

Khan, M. A., Miyoshi, H., Gallie, D. R., and Goss, D. J. 2008. Potyvirus genome-linked protein, $\mathrm{VPg}$, directly affects wheat germ in vitro translation: Interactions with translation initiation factors eIF4F and eIFiso4F. J. Biol. Chem. 283:1340-1349.

Krause-Sakate, R., Le Gall, O., Fakhfakh, H., Peypelut, M., Marrakchi, M., Varveri, C., Pavan, M. A., Souche, S., Lot, H., Zerbini, F. M., and Candresse, T. 2002. Molecular and biological characterization of Lettuce mosaic virus (LMV) isolates reveals a distinct and widespread type of resistance-breaking isolate: LMV-Most. Phytopathology 92:563-572.

Lafforgue, G., Tromas, N., Elena, S. F., and Zwart, M. P. 2012. Dynamics of the establishment of systemic Potyvirus infection: Independent yet cumulative action of primary infection sites. J. Virol. 86:12912-12922.
Léonard, S., Plante, D., Wittmann, S., Daigneault, N., Fortin, M. G., and Laliberté, J. F. 2000. Complex formation between potyvirus VPg and translation eukaryotic initiation factor 4E correlates with virus infectivity. J. Virol. 74:7730-7737.

Mäkinen, K., and Hafrén, A. 2014. Intracellular coordination of potyviral RNA functions in infection. Front. Plant Sci. 5:110.

Martínez, F., Rodrigo, G., Aragonés, V., Ruiz, M., Lodewijk, I., Fernández, U., Elena, S. F., and Daròs, J.-A. 2016. Interaction network of tobacco etch potyvirus NIa protein with the host proteome during infection. BMC Genomics 17:87.

Mayberry, L. K., Dennis, M. D., Leah Allen, M., Ruud Nitka, K., Murphy, P. A., Campbell, L., and Browning, K. S. 2007. Expression and purification of recombinant wheat translation initiation factors eIF1, eIF1A, eIF4A, eIF4B, eIF4F, eIF(iso)4F, and eIF5. Methods Enzymol. 430:397-408.

Miyoshi, H., Okade, H., Muto, S., Suehiro, N., Nakashima, H., Tomoo, K., and Natsuaki, T. 2008. Turnip mosaic virus VPg interacts with Arabidopsis thaliana $\mathrm{eIF}$ (iso)4E and inhibits in vitro translation. Biochimie 90:1427-1434.

Moury, B., Fabre, F., and Senoussi, R. 2007. Estimation of the number of virus particles transmitted by an insect vector. Proc. Natl. Acad. Sci. U.S.A. 104:17891-17896.

Murphy, J. F., Rychlik, W., Rhoads, R. E., Hunt, A. G., and Shaw, J. G. 1991. A tyrosine residue in the small nuclear inclusion protein of tobacco vein mottling virus links the VPg to the viral RNA. J. Virol. 65:511-513.

Nault, L., Taofifenua, C., Anne, A., Chovin, A., Demaille, C., Besong-Ndika, J., Cardinale, D., Carette, N., Michon, T., and Walter, J. 2015. Electrochemical atomic force microscopy imaging of redox-immunomarked proteins on native potyviruses: From subparticle to single-protein resolution. ACS Nano 9:4911-4924.

Rantalainen, K. I., Uversky, V. N., Permi, P., Kalkkinen, N., Dunker, A. K., and Mäkinen, K. 2008. Potato virus A genome-linked protein VPg is an intrinsically disordered molten globule-like protein with a hydrophobic core. Virology 377:280-288.

Revers, F., and García, J. A. 2015. Molecular Biology of Potyviruses. Pages 101-199 in: Advances in Virus Research. Maramorosch, K., and Mettenleiter, T. C., eds. Academic Press, Burlington.

Roudet-Tavert, G., German-Retana, S., Delaunay, T., Delécolle, B., Candresse, T., and Le Gall, O. 2002. Interaction between potyvirus helper component-proteinase and capsid protein in infected plants. J. Gen. Virol. 83:1765-1770.

Roudet-Tavert, G., Michon, T., Walter, J., Delaunay, T., Redondo, E., and Le Gall, O. 2007. Central domain of a potyvirus VPg is involved in the interaction with the host translation initiation factor eIF4E and the viral protein HcPro. J. Gen. Virol. 88:1029-1033.

Ruiz-Ferrer, V., Boskovic, J., Alfonso, C., Rivas, G., Llorca, O., LópezAbella, D., and López-Moya, J. J. 2005. Structural analysis of tobacco etch potyvirus HC-pro oligomers involved in aphid transmission. J. Virol. 79:3758-3765.

Strudwick, S., and Borden, K. L. B. 2002. The emerging roles of translation factor eIF4E in the nucleus. Differentiation 70:10-22.

Thébaud, G., Chadoeuf, J., Morelli, M. J., McCauley, J. W., and Haydon, D. T. 2010. The relationship between mutation frequency and replication strategy in positive-sense single-stranded RNA viruses. Proc. Biol. Sci. 277:809-817.

Torrance, L., Andreev, I. A., Gabrenaite-Verhovskaya, R., Cowan, G., Mäkinen, K., and Taliansky, M. E. 2006. An unusual structure at one end of potato potyvirus particles. J. Mol. Biol. 357:1-8.

Tromas, N., Zwart, M. P., Lafforgue, G., and Elena, S. F. 2014. Within-host spatiotemporal dynamics of plant virus infection at the cellular level. PLoS Genet. 10:e1004186.

Wang, A. 2015. Dissecting the molecular network of virus-plant interactions: The complex roles of host factors. Annu. Rev. Phytopathol. 53:45-66.

Zhang, J., Roberts, R., and Rakotondrafara, A. M. 2015. The role of the 5' untranslated regions of Potyviridae in translation. Virus Res. 206:74-81. 